\title{
Efflux pump genes and antimicrobial resistance of Pseudomonas aeruginosa strains isolated from lower respiratory tract infections acquired in an intensive care unit
}

\author{
Burcin Ozer ${ }^{1}$, Nizami Duran ${ }^{1}$, Yusuf Onlen ${ }^{2}$ and Lutfu Savas ${ }^{2}$
}

The aim of this study was to determine the antimicrobial resistance rates and the resistance genes associated with efflux pumps of Pseudomonas aeruginosa strains isolated from the patients who acquired lower respiratory tract infection (LRTI) in intensive care unit (ICU). Fifty $P$. aeruginosa strains isolated from the lower respiratory tract specimens of the patients who acquired LRTIs in ICU were included in this study. $P$. aeruginosa strains were isolated from tracheal aspirate (27), bronchoalveolar lavage (14) and sputum (9). The susceptibilities of the isolates were investigated by the disk diffusion method. Multiplex PCR assay was carried out for the detection of 13 antibiotic-resistance genes. Antimicrobial resistance rates of the isolates were found high and the highest resistance rate of the isolates studied was determined against to mezlocillin (50\%) followed by norfloxacin $(48 \%)$, ciprofloxacin $(46 \%)$, meropenem $(40 \%)$. Fourty-three isolates $(86 \%)$ were determined to carry one and more resistance genes. NfXB gene was most often determined in the genes that were investigated. The significant relation between the resistance to cefepime, piperacilline/tazobactam and the $\operatorname{mex} C$ gene, that between the resistance to mezlocillin, piperacilline/tazobactam, ceftazidime, cefepime and ampC genes, and that between the resistance to ciprofloxacin, norfloxacin and oprJ, oprN and $n f x B$ genes was identified. Resistance caused by genes for carbapenemases, aminoglycoside-modifying enzymes and other mechanisms were not identified in this study. Understanding the prevalence and mechanism of antimicrobial resistance in $P$. aeruginosa may help to select empirical therapy for nosocomial LRTIs due to $P$. aeruginosa in our ICU. The Journal of Antibiotics (2012) 65, 9-13; doi:10.1038/ja.2011.102; published online 16 November 2011

Keywords: intensive care unit; lower respiratory tract infection; P. aeruginosa; resistance genes

\section{INTRODUCTION}

Nosocomial lower respiratory tract infection (LRTI) is the most frequent hospital acquired infection. It is the most common cause of death among nosocomial infections and is the primary cause of death in intensive care units (ICUs). ${ }^{1}$ Pseudomonas aeruginosa is an important pathogen of nosocomial LRTI especially in ICUs and is commonly resistant to many antibiotics. ${ }^{2}$ Multidrug-resistant (MDR) P. aeruginosa (resistant to at least three of the following antimicrobials: ceftazidime, imipenem, gentamicin and ciprofloxacin) are often isolated from nosocomial infections in ICUs. ${ }^{2}$ MDR is often related to the specific efflux pumps and porins in $P$. aeruginosa strains. ${ }^{3,4}$ And four efflux pumps, all of the Resistance Nodule Cell Division Family (RND) type, have been described as MexAB-OprM, MexCD-OprJ, $M e x E F-O p r N$ and MexXY-OprM, and an outer membrane porin $(O p r D)$. Three genes encoding these pumps are arranged as operons. The first gene encoding a membrane fusion protein that is associated with the cytoplasmic membrane (MexA, MexC, MexE and MexX). The second gene encodes the transporter $(\operatorname{MexB}, \operatorname{MexD}, \operatorname{MexF}$ and $M e x Y)$ thought to export the substrate across the inner membrane. The third gene encodes an outer membrane protein (OprM, OprJ and OprN) that facilitates passage of the substrate across the outer membrane. ${ }^{5}$ In many ICUs, MDR P. aeruginosa isolates represent a major therapeutic problem. Therefore, understanding the mechanisms of resistance and developing therapy alternatives for these isolates is very important.

The aim of this study was to determine the antimicrobial resistance rates and the resistance genes of $P$. aeruginosa strains isolated from the patients who had LRTI in ICU.

\section{MATERIALS AND METHODS}

The strains were collected during the period February 2007-April 2009 from the patients who acquired LRTIs in ICU of Mustafa Kemal University Hospital. This study was approved by the Local Ethical Committee and was carried out in Mustafa Kemal University, School of Medicine, Department of Medical Microbiology.

${ }^{1}$ Mustafa Kemal University, School of Medicine, Department of Medical Microbiology, Hatay, Turkey and ${ }^{2}$ Mustafa Kemal University, School of Medicine, Department of Infectious Disease and Clinical Microbiology, Hatay, Turkey

Correspondence: Dr B Ozer, Mustafa Kemal University, School of Medicine, Department of Medical Microbiology, Hatay 31040, Turkey.

E-mail: burcinozer@yahoo.com

Received 17 February 2011; revised 3 October 2011; accepted 7 October 2011; published online 16 November 2011 


\section{Bacterial strains}

Fifty $P$. aeruginosa strains isolated from the lower respiratory tract specimens of the patients who acquired LRTIs in ICU were included in this study. P. aeruginosa strains (fifty) were isolated from tracheal aspirate (27), bronchoalveolar lavage (14) and sputum (9). Isolates were identified as P. aeruginosa based on colony morphology, odor, Gram staining, production of blue-green pigment on Mueller Hinton agar, reactions $(\mathrm{k} / \mathrm{k})$ on triple sugar iron agar slants, positive oxidase reaction. ${ }^{5}$ The species identification was confirmed with the Vitek 2 compact system (bioMérieux, Marcy l'Etoile, France) as required.

\section{Antibiotic susceptibility testing}

The isolates were evaluated for their susceptibilities to mezlocillin $(75 \mu \mathrm{g})$, piperacillin/tazobactam $(100 / 10 \mu \mathrm{g})$, ceftazidime $(30 \mu \mathrm{g})$, cefepime $(30 \mu \mathrm{g})$, imipenem $(10 \mu \mathrm{g})$, meropenem $(10 \mu \mathrm{g})$, gentamicin $(10 \mu \mathrm{g})$, amikacin $(30 \mu \mathrm{g})$, tobramicin $(10 \mu \mathrm{g})$, ciprofloxacin $(5 \mu \mathrm{g})$, and norfloxacin $(10 \mu \mathrm{g}$; Oxoid, Basingstoke, UK) by the disk diffusion method, and evaluated according to Clinical and Laboratory Standards Institute. ${ }^{6}$

\section{Determination of the resistance genes by PCR}

Bacterial DNA was extracted from the strains using the method of Chen and $\mathrm{Kuo}^{7}$ with some modifications. The primers of resistance genes were selected from a research article of Dumas et al., ${ }^{8}$ shown in Table 1. Multiplex PCR assay was carried out for the detection of antibiotic-resistance genes in a thermal cycler (Bioder/Thermal Blocks xp cycler, Tokyo Japan). The primers were selected according to their base pair. There were four primer groups including; $\operatorname{mexE}(114 \mathrm{bp}), \operatorname{mexR}(150 \mathrm{bp}), \operatorname{mexT}(216 \mathrm{bp}), \operatorname{mexA}(316 \mathrm{bp}$ ) as the first, oprD (156bp), oprD (232 bp) and oprJ (305 bp) as the second, mexC (164 bp), mexC (344 bp) and $\operatorname{ampC}(218 \mathrm{bp}$ ) as the third, and $n f x B$ (164 bp), oprN (235 bp) and $\operatorname{mex} X(326 \mathrm{bp})$ as the fourth group.

The PCR amplification was carried out in a total volume of $25 \mu \mathrm{l}$ reaction mixture. PCR amplification was performed as follows: The reaction mixture consisted of $2.5 \mathrm{ml}$ of $10 \times$ reaction buffer without $\mathrm{MgCl}_{2}$ (Promega, Madison, WI, USA); $200 \mu \mathrm{M}$ of each deoxynucleoside triphosphate (ABgene, Epsom, UK), $2 \mathrm{mM} \mathrm{MgCl}_{2} ; 0.4 \mu \mathrm{M}$ of primers and $\sim 10 \mathrm{ng}$ of template DNA, and brought up to a $25 \mu \mathrm{l}$ final volume with distilled water. Reactions were started at $94{ }^{\circ} \mathrm{C}$ for $4 \mathrm{~min}$ and placed on ice, and $1 \mathrm{U}$ of Taq polymerase (Fermentas, Hanover, MD, USA) was added. The amplification process was started with an initial denaturation step $\left(94^{\circ} \mathrm{C}, 1 \mathrm{~min}\right)$. Each cycle consists of three steps (denaturation, annealing and extension). PCR reaction consisted of 35 cycles of amplification for only mexA, mexT, mexE and mexR genes. The other PCR reaction consisted of 30 cycles of amplification. Amplification consisted of denaturation at $94{ }^{\circ} \mathrm{C}$ for $1 \mathrm{~min}$, annealing at $57^{\circ} \mathrm{C}$ for $45 \mathrm{~s}$ and DNA chain extension at $72{ }^{\circ} \mathrm{C}$ for $45 \mathrm{~s}$. And a final extension cycle was performed at $72{ }^{\circ} \mathrm{C}$ for $10 \mathrm{~min}$. After the amplification of antibiotic-resistance genes, $10 \mu \mathrm{l}$ volumes of PCR samples were mixed with $3 \mu \mathrm{L}$ of loading buffer $(10 \%$ (w/v), ficoll 400 ; $10 \mathrm{mmoll}^{-1}$ Tris-HCl, pH 7.5; $50 \mathrm{mmoll}^{-1}$ EDTA; $0.25 \%$ bromophenol blue). The PCR products were analyzed in a $2 \%(\mathrm{w} / \mathrm{v})$ agarose gel in $1 \times$ TAE buffer ( $40 \mathrm{mmoll}^{-1}$ Tris-acetate, $1 \mathrm{mmoll}^{-1}$ EDTA). Ethidium bromide $\left(0.5 \mu \mathrm{g} \mathrm{ml}^{-1}\right.$ TAE)-stained DNA amplicons were visualized using a gel imaging system (Wealtec, Dolphin-View, NV, USA). To determine the expected bp lengths, DNA marker with defined molecular weights in the range 100-2000 were used.

\section{Statistical methods}

Analysis was performed using Statistical Package for Social Sciences version 13.0 (SSPS Inc, Chicago, IL, USA). Comparison for categorical variables was calculated using $\chi^{2}$ test. A $P$-value $<0.05$ was considered statistically significant.

\section{RESULTS}

The highest resistance rate was found against to mezlocillin (50\%), followed by norfloxacin (48\%), ciprofloxacin (46\%), meropenem (40\%; Table 2). We measured gene expression of seven mex efflux pumps, the chromosomal ampC $\beta$-lactamase, the porin oprD, oprJ, $\operatorname{oprN}$ and $n f x B$ in clinical isolates. Expression of mexA, mexE, mexR, mexT genes in group one, oprD and oprJ genes in group two, ampC and mexC genes in group three and $n f x B, o p r N$ and mexX genes in group four is shown in Figures 1-4, respectively.
Table 1 Primer sequences used in the study

\begin{tabular}{|c|c|c|c|}
\hline Primer & 5'-sequence-3' & Length (bp) & $\begin{array}{c}\text { Product } \\
\text { length (bp) }\end{array}$ \\
\hline $\operatorname{mexR} 1$ & CGCGAGCTGGAGGGAAGAAACC & 22 & 150 \\
\hline $\operatorname{mexR} 2$ & CGGGGCAAACAACTCGTCATGC & 22 & \\
\hline $\operatorname{mexA1}$ & CGACCAGGCCGTGAGCAAGCAGC & 23 & 316 \\
\hline $\operatorname{mexA2}$ & GGAGACCTTCGCCGCGTTGTCGC & 23 & \\
\hline nfxB1 & CGCCTGATCAAGGAACACCTCACC & 24 & 164 \\
\hline mfxB2 & CGAAACACGCCTTTCTGCTGTCC & 23 & \\
\hline $\operatorname{mexC} 1$ & ATCCGGCACCGCTGAAGGCTGCG & 23 & 344 \\
\hline $\operatorname{mexC2}$ & CGGATCGAGCTGCTGGATGCGCG & 23 & \\
\hline $\operatorname{mexC3}$ & GTACCGGCGTCATGCAGGGTTC & 22 & 164 \\
\hline $\operatorname{mexC4}$ & TTACTGTTGCGGCGCAGGTGACT & 23 & \\
\hline oprJ1 & GTTCCGGGCCTGAATGCCGCTGC & 23 & 305 \\
\hline oprJ2 & TCGCGGCTGACCAGGGTCTGACG & 23 & \\
\hline $\operatorname{mex} \times 1$ & TGAAGGCGGCCCTGGACATCAGC & 23 & 326 \\
\hline $\operatorname{mex} x 2$ & GATCTGCTCGACGCGGGTCAGCG & 23 & \\
\hline $\operatorname{mexT1}$ & CAGCACCGCGGTGTTCCGCATCG & 23 & 216 \\
\hline $\operatorname{mexT2}$ & ACGGTCTTGCGCTTGGCGTTGGC & 23 & \\
\hline mexE4 & CCAGGACCAGCACGAACTTCTTGC & 24 & 114 \\
\hline mexE5 & CGACAACGCCAAGGGCGAGTTCACC & 25 & \\
\hline oprN1 & CAACCGGGAGTGACCGAGGACCG & 23 & 235 \\
\hline oprN2 & TGCTCAGGGCAATCTTCTCGCGC & 23 & \\
\hline ampC1 & CGGCTCGGTGAGCAAGACCTTC & 22 & 218 \\
\hline ampC2 & AGTCGCGGATCTGTGCCTGGTC & 22 & \\
\hline oprD1 & ATCTACCGCACAAACGATGAAGG & 23 & 156 \\
\hline oprD2 & GCCGAAGCCGATATAATCAAACG & 23 & \\
\hline oprD3 & CTCGACGGCACCTCCGACAAGAC & 23 & 232 \\
\hline oprD4 & AGCCCTTCGAATTCGCTGCTCTG & 23 & \\
\hline
\end{tabular}

Table 2 The resistance rates of strains by the disk diffusion method

\begin{tabular}{lc}
\hline Antibiotics & Number (\%) \\
\hline Mezlocillin & $25(50)$ \\
Norfloxacin & $24(48)$ \\
Ciprofloxacin & $23(46)$ \\
Meropenem & $20(40)$ \\
Gentamicin & $19(38)$ \\
Tobramicin & $18(36)$ \\
Imipenem & $18(36)$ \\
Ceftazidime & $15(30)$ \\
Piperacilline/tazobactam & $12(24)$ \\
Cefepime & $9(18)$ \\
Amikacin & $8(16)$
\end{tabular}

Seven of 50 P. aeruginosa strains had none of these resistance genes. Fourty-three isolates $(86 \%)$ were determined to be positive for one and more resistance genes. Only four isolates were found to be positive for one resistance gene. The presence of the resistance genes by multiplex PCR is shown in Table 3.

Number of the resistant isolates to cefepime and piperacilline/ tazobactam carrying mexC gene were found to be 12 (24\%; $P=0.048)$ and $15(30 \% ; P=0.025)$, respectively; and the number of the resistant isolates to mezlocillin, piperacilline/tazobactam, ceftazidime and cefepime-carrying $a m p C$ gene were found to be $16(32 \%$; $P=0.002), 15$ (30\%; $P=0.002), 12(24 \% ; P=0.035)$ and $12(24 \%$; $P=0.008)$, respectively. The isolates carrying $n f x B$, oprN and oprJ genes 


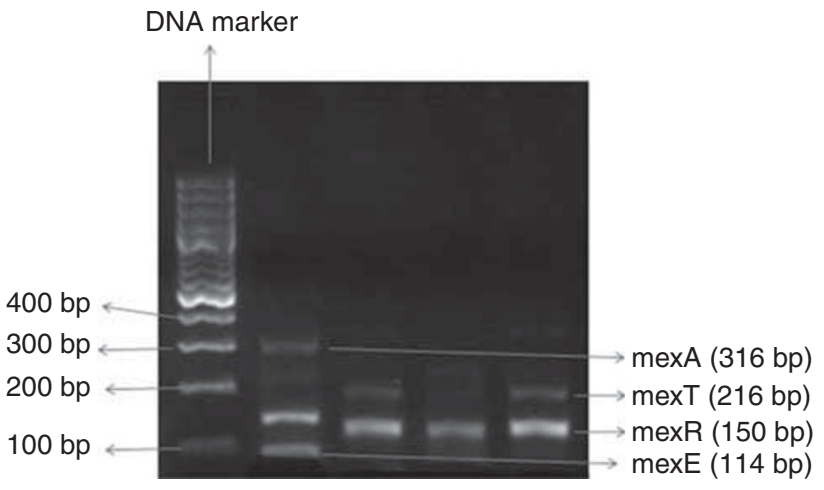

Figure 1 Multiplex PCR amplification products showing expression of the $\operatorname{mexA}$, mexT, mexR and mexE genes of $P$. aeruginosa. A 100-bp DNA size ladder is shown; $100 \mathrm{bp}$ DNA size ladder includes fragments of 3000 , 2000, 1500, 1200, 1000, 900, 800, 700, 600, 500, 400, 300, 200 and $100 \mathrm{bp}$.

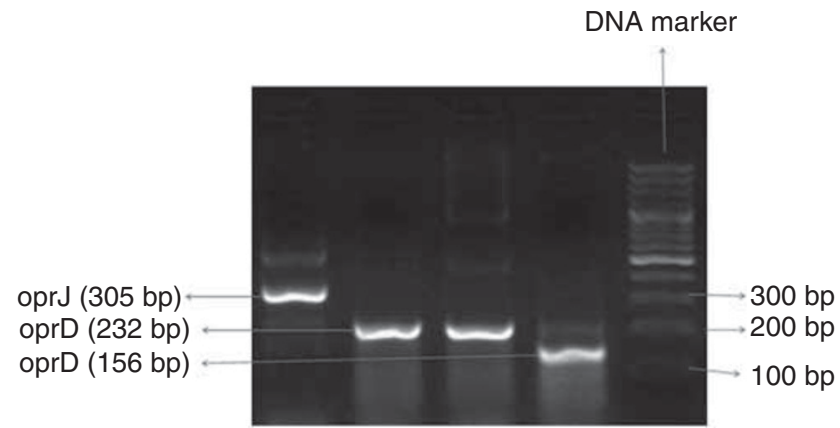

Figure 2 Multiplex PCR amplification products showing expression of the oprJ and oprD genes of $P$. aeruginosa. A 100-bp DNA size ladder is shown.

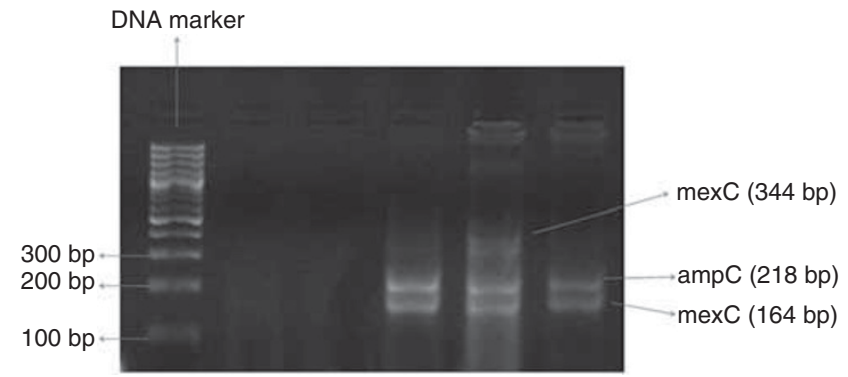

Figure 3 Multiplex PCR amplification products showing expression of the mexC and ampC genes of $P$. aeruginosa. A 100-bp DNA size ladder is shown.

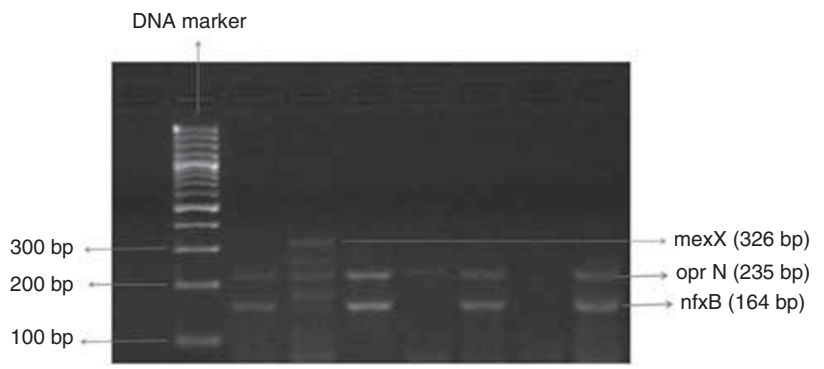

Figure 4 Multiplex PCR amplification products showing expression of the $\operatorname{mex} X, \operatorname{oprN}, n f x B$ genes of $P$. aeruginosa. A 100-bp DNA size ladder is shown.
Table 3 The presence of antibiotic resistance genes in Pseudomonas aeruginosa by multiplex PCR method

\begin{tabular}{lc}
\hline Genes (bp) & Isolate number (\%) \\
\hline$n f x B(164)$ & $32(64)$ \\
$\operatorname{oprN}(235)$ & $26(52)$ \\
$\operatorname{mexE}(114)$ & $26(52)$ \\
$\operatorname{mexC}(164)$ & $24(48)$ \\
$\operatorname{ampC}(218)$ & $21(42)$ \\
$\operatorname{oprD}(232)$ & $21(42)$ \\
$\operatorname{mex} R(150)$ & $17(34)$ \\
$\operatorname{mexC}(344)$ & $12(24)$ \\
$\operatorname{oprJ}(305)$ & $11(22)$ \\
$\operatorname{oprD}(156)$ & $9(18)$ \\
$\operatorname{mexA}(316)$ & $7(14)$ \\
$\operatorname{mex} T(216)$ & $5(10)$ \\
$\operatorname{mexX}(326)$ & $2(4)$ \\
\hline
\end{tabular}

were found to be more resistant to norfloxacin and ciprofloxacin $(P<0.05)$. The relationship between antibiotic resistance and the presence of the resistance genes is shown in Table 4.

\section{DISCUSSION}

$P$. aeruginosa is an important pathogen associated with serious nosocomial infections. In 2003, $P$. aeruginosa was reported to be the most commonly isolated Gram-negative bacteria (18.1\%) for nosocomial pneumonia in the United States. ${ }^{9}$ Inside and outside ICUs, MDR- $P$. aeruginosa strains has becoming an increasingly reported problem. ${ }^{10}$ The ICU isolates gained significant resistance to the antibiotics used for the treatment of the life-threatening infections in ICUs. ${ }^{10}$ Increasing resistance rates to the antibiotics in P. aeruginosa strains were reported by several studies during the last years. ${ }^{10-13}$

In this study, 50 P. aeruginosa isolates from the patients with LRTIs in ICU were investigated for 13 genes, mostly for efflux proteins leading to antimicrobial resistance. To our knowledge, although there are studies investigating the resistance genes from Turkey, ${ }^{14,15}$ there aren't any studies investigating a large number of resistance genes in $P$. aeruginosa strains isolated from nosocomial LRTIs. The results of the study have shown antimicrobial resistance rates of the isolates were found high, and $86 \%$ of them were determined to carry at least one resistance gene. $P$. aeruginosa exhibited the highest rates of resistance to mezlocillin, with resistance to norfloxacin and ciprofloxacin ranging from 46 to $50 \%$. In the National Surveillance Program in USA, it was reported that antimicrobial resistance was highest for the betalactams and ciprofloxacin. ${ }^{13}$ Our findings support the results of that study. In our study, the resistance rates of $P$. aeruginosa were higher than the resistance rates in multicenter study in Spain ${ }^{12}$ and lower than the resistance rates in the study from Bulgaria. ${ }^{11}$

Beta lactams in combination with aminoglycosides are commonly used as antipseudomonal agents because they may exhibit synergy with aminoglycosides. ${ }^{16}$ In the current study, the highest resistance rate of the isolates were determined against mezlocillin (50\%). The resistance rates against other beta lactams; ceftazidime, piperacilline/ tazobactam and cefepime were determined to be $30,24,18$ and $16 \%$, respectively. These resistance rates were lower than the study performed in an another university hospital in Turkey. ${ }^{17}$ Antipseudomonal beta lactam antibiotics (piperaciline, cefepime and meropenem) are among mexCD-OprJ's substrates. ${ }^{18}$ We found that the 
Table 4 Relationship between antibiotic resistance and the presence of the resistance genes

\begin{tabular}{|c|c|c|c|c|c|c|c|c|c|c|c|c|c|c|c|c|c|c|c|c|c|c|}
\hline \multirow[b]{2}{*}{$\begin{array}{l}\text { Resistance } \\
\text { to antibiotics }\end{array}$} & \multicolumn{2}{|c|}{$\operatorname{mex} A$} & \multicolumn{2}{|c|}{$\operatorname{mexc}$} & \multicolumn{2}{|c|}{$\operatorname{mex} E$} & \multicolumn{2}{|c|}{$\operatorname{mex} X$} & \multicolumn{2}{|c|}{$\operatorname{mex} R$} & \multicolumn{2}{|c|}{$\operatorname{mex} T$} & \multicolumn{2}{|c|}{ oprD } & \multicolumn{2}{|c|}{ oprJ } & \multicolumn{2}{|c|}{ oprN } & \multicolumn{2}{|c|}{$n f x B$} & \multicolumn{2}{|c|}{$a m p C$} \\
\hline & $\begin{array}{l}\text { Pos. } \\
\text { (n) }\end{array}$ & $\begin{array}{l}\text { Neg. } \\
(n)\end{array}$ & $\begin{array}{l}\text { Pos. } \\
\text { (n) }\end{array}$ & $\begin{array}{l}\text { Neg. } \\
(n)\end{array}$ & $\begin{array}{l}\text { Pos. } \\
\text { (n) }\end{array}$ & $\begin{array}{l}\text { Neg. } \\
(n)\end{array}$ & $\begin{array}{l}\text { Pos. } \\
\text { (n) }\end{array}$ & $\begin{array}{l}\text { Neg. } \\
\text { (n) }\end{array}$ & $\begin{array}{l}\text { Pos. } \\
\text { (n) }\end{array}$ & $\begin{array}{l}\text { Neg. } \\
(n)\end{array}$ & $\begin{array}{l}\text { Pos. } \\
\text { (n) }\end{array}$ & $\begin{array}{l}\text { Neg. } \\
(n)\end{array}$ & $\begin{array}{l}\text { Pos. } \\
\text { (n) }\end{array}$ & $\begin{array}{l}\text { Neg. } \\
(n)\end{array}$ & $\begin{array}{l}\text { Pos. } \\
\text { (n) }\end{array}$ & $\begin{array}{l}\text { Neg. } \\
(n)\end{array}$ & $\begin{array}{l}\text { Pos. } \\
\text { (n) }\end{array}$ & $\begin{array}{l}\text { Neg. } \\
(n)\end{array}$ & $\begin{array}{l}\text { Pos. } \\
\text { (n) }\end{array}$ & $\begin{array}{l}\text { Neg. } \\
(n)\end{array}$ & $\begin{array}{l}\text { Pos. } \\
\text { (n) }\end{array}$ & $\begin{array}{l}\text { Neg. } \\
\text { (n) }\end{array}$ \\
\hline Piperacilline/tazobactam & 3 & 20 & $15^{*}$ & 8 & & & 1 & 22 & & & 1 & 22 & & & & & & & & & $15^{*}$ & 8 \\
\hline Mezlocillin & & & & & & & & & & & & & & & & & & & & & $16^{*}$ & 9 \\
\hline Cefepim & 3 & 15 & $12^{*}$ & 6 & & & 1 & 17 & 7 & 11 & 1 & 17 & & & 6 & 12 & 12 & 6 & & & $12^{*}$ & 6 \\
\hline Imipenem & & & & & & & 0 & 18 & & & 1 & 17 & 7 & 7 & 5 & 13 & 12 & 6 & & & & \\
\hline Norfloxacin & 3 & 21 & & & 13 & 11 & 1 & 23 & 8 & 16 & 2 & 22 & & & $9 *$ & 15 & $16^{*}$ & 8 & $24^{*}$ & 0 & & \\
\hline Ciprofloxacin & 3 & 21 & & & 13 & 11 & 1 & 23 & 8 & 16 & 2 & 22 & & & $9 *$ & 15 & $16^{*}$ & 8 & $24 *$ & 0 & & \\
\hline Amikacin & & & & & & & 1 & 13 & & & & & & & & & & & & & & \\
\hline Gentamicin & & & & & & & 1 & 20 & & & & & & & & & & & & & & \\
\hline Tobramicin & & & & & & & 1 & 18 & & & & & & & & & & & & & & \\
\hline
\end{tabular}

Abbreviations: neg., negative; pos., positive.

${ }^{*} P<0.05$.

isolates carrying mexC gene were more resistant to cefepime and piperacilline/tazobactam.

Beta lactam antibiotics (piperacilline, ceftazidime, cefepime aztreonam and meropenem) are substrats of mexAB-OprM. ${ }^{19}$ Also, no significant relation was determined between mexA gene and ceftazidime, cefepime and piperacilline/tazobactam resistance. Piperacilline, cefepime, ceftazidime, meropenem, imipenem are substrats of mexXY-OprM efflux system. ${ }^{18}$ Furthermore, no significant relation between mexX gene and resistance against these antibiotics was found.

MexR negatively regulates mexAB-oprM efflux system. ${ }^{20}$ However, no relation was found between mexR gene and resistance against ceftazidime, cefepime and meropenem in our study.

$A m p C$ gene causes production of chromosomal beta lactamase. The overproduction of $A m p C$ beta lactamases can result in resistance to nearly all beta-lactam antibiotics except the carbapenems. ${ }^{21}$ We found that isolates carrying $a m p C$ gene were more resistant to mezlocillin, piperacilline/tazobactam, ceftazidime and cefepime.

mexT negatively regulates mexAB-oprM efflux system and oprD. ${ }^{22}$ We didn't find a significant relation between mexT gene and ceftazidime, cefepime, piperacilline/tazobactam, imipenem and meropenem (the substrates of mexAB-oprM efflux system and oprD).

Carbapenems are one of the most active groups of beta lactam antibiotics against $P$. aeruginosa. The outer membrane protein $O \operatorname{prD}$ allows entry of carbapenems, and its reduced expression is frequently noted in carbapenem-resistant isolates. ${ }^{23}$ In this study, no relation was found between the persistence of the oprD gene and susceptibility of carbapenems. Outer membrane proteins; oprJ and oprN are related to multidrug resistance. ${ }^{23}$ No relation between the antibiotics (cefepime, imipenem and meropenem) that were investigated in the other studies and these genes (oprJ and oprN) was determined in this study.

Carbapenem remains as an important agent for the therapy of serious infections secondary to MDR $P$. aeruginosa. The development of carbapenem resistance severely compromises effective therapeutic options. In the absence of carbapenem-hydrolyzing enzymes, the mechanism leading to carbapenem resistance is usually multifactorial. We determined that the isolates that were resistant to carbapenems were also resistant to other beta lactam antibiotics in this study. Only one isolate was resistant to carbapenems and didn't show cross- resistance to other beta lactams so it can be imipenem-resistant $P$. aeruginosa mutant. ${ }^{24}$

We investigated the relation between $\operatorname{mexA}, \operatorname{mexC}, \operatorname{mexX}$, $m e x E$ genes and quinolones because they are substrates of four efflux system but we didn't find. We also found no relation between mexR gene that negatively regulates mexAB-oprM, and mexT gene that positively regulates mexCD-oprJ and the resistance against the antibiotics.

The isolates carrying oprJ and oprN, which cause multidrug resistance, and $n f x B$ gene were determined to be more resistant to ciprofloxacin and norfloxacin.

Aminoglycosides are frequently used in pseudomonal infections. ${ }^{16}$ In our study, the aminoglycoside resistance rates in $P$. aeruginosa were lower than that in the study from Korea. ${ }^{25}$ Aminoglycoside resistance arises more frequently via enzymatic modification of the aminoglycosides, and less frequently via mexXY-oprM efflux systems. ${ }^{16}$ So no relation was found between the presence of mexX gene and aminoglycosides (amikacin, gentamicin and tobramycin).

\section{CONCLUSION}

These data showed that antimicrobial resistance rates of the isolates were high and the highest resistance was against mezlocillin. Most of the isolates were determined to carry one and more resistance genes. $N f x B$ gene was most often seen in the genes that were investigated.

There were strains that were susceptible to most of the antibiotics although they contained large number of antibiotic resistance genes. These strains have very high chance of developing resistance during treatment. And also it should be remembered that the mechanism leading to antimicrobial resistance is usually multifactorial. For this reason, rather than investigating the susceptibility to antimicrobials by phenotypic methods, investigating genotypically the antimicrobial-resistance genes is more meaningful. Understanding the prevalence and mechanism of antimicrobial resistance may help to select empirical therapy for nosocomial LRTIs due to P. aeruginosa in our ICU.

\section{ACKNOWLEDGEMENTS}

This work was granted by Mustafa Kemal University Scientific Research Projects (BAP 08T 1701). 
1 Hernández, G., Rico, P., Díaz, E. \& Rello, J. Nosocomial lung infections in adult intensive care units. Microbes Infect. 6, 1004-1014 (2004).

2 Vanhems, P. et al. Nosocomial pulmonary infection by antimicrobial-resistant bacteria of patients hospitalized in intensive care units: risk factors and survival. J. Hosp. Infect. 45, 98-106 (2000).

3 Poole, K. Efflux-mediated resistance to fluoroquinolones in gram-negative bacteria. Antimicrob. Agents Chemother. 44, 2233-2241 (2000).

4 Poole, K. Multidrug efflux pumps and antimicrobial resistance in Pseudomonas aeruginosa and related organisms. J. Mol. Microbiol. Biotechnol. 3, 255-264 (2001).

5 Kiska, D. L. \& Gilligan, P. H. In: Man. Clin. Microbio. 8th edn (eds Muray PR, Baron EJ, Jorgensen JH, Pfaller MA, Yolken RH) (ASM Press, Washington, 2003).

6 Clinical and Laboratory Standards Institute. Performance Standards for Antimicrobial Susceptibility Testing-Nineteenth Informational Supplement. CLSI document M100S21 (Clinical and Laboratory Standards Institute, Wayne, Pennsylvania, USA, 2011).

7 Chen, W. \& Kuo, T. A simple and rapid method for the preparation of gram negative bacterial genomic DNA. Nucleic Acids Res. 21, 2260 (1993).

8 Dumas, J. L., van Delden, C., Peron, K. \& Köhler, T. Analysis of antibiotic resistance gene expression in Pseudomonas aeruginosa by quantitative real-time-PCR. FEMS Microbiol. Lett. 254, 217-225 (2006)

9 Gaynes, R. \& Edwards, J. R. Overview of nosocomial infections caused by gram-negative bacilli. Clin. Infect. Dis. 41, 848-854 (2005).

10 Karlowsky, J. A., Draghi, D. C., Jones, M. E., Thornsberry, C., Friedland, I. R. \& Sahm, D. F. Surveillance for antimicrobial susceptibility among clinical isalates of Pseudomonas aeruginosa and Acinetobacter baumannii from hospitalized patients in the United States, 1998 to 2002. Antimicrob. Agents. Chemother. 47, 1681-1688 (2003).

11 Strateva, T., Ouzounova Raykova, V., Markova, B., Todorova, A., Marteva Proevska, Y. \& Mitov, I. Problematic clinical isolates of Pseudomonas aeruginosa from the university hospitals in Sofia, Bulgaria: current status of antimicrobial resistance and prevailing resistance mechanisms. J. Med. Microbiol. 56, 956-963 (2007).

12 Sánchez-Romero, I. et al. Evolution of the antimicrobial resistance of Pseudomonas aeruginosa in Spain: Second National Study (2003). Rev. Esp. Quimioterap. 20, 222-229 (2007).

13 Obritsch, M. D., Fish, D. N., MacLaren, R. \& Jung, R. National surveillance of antimicrobial resistance in Pseudomonas aeruginosa isolates obtained from intensive care unit patients from 1993 to 2002. Antimicrob. Agents Chemother. 48, 4606-4610 (2004).

14 Savli, H. et al. Expression stability of six housekeeping genes: a proposal for resistance gene quantification studies of Pseudomonas aeruginosa by real-time quantitative RT-PCR. J. Med. Microbiol. 52, 1-6 (2003).

15 Kolayli, F. et al. Effect of carbapenems on the transcriptional expression of the oprD, OprM, OprN genes in Pseudomona aeruginosa. J. Med. Microbiol. 53, 915-920 (2004).

16 Poole, K. Aminoglycoside resistance in Pseudomonas aeruginosa. Antimicrob. Agents Chemother. 49, 479-487 2005.

17 Ozer, B., Tatman-Otkun, M., Memis, D. \& Otkun, M. Characteristics of Pseudomonas aeruginosa isolates from intensive care unit. Cent. Eur. J. Med. 4, 156-163 (2009).

18 Masuda, N. et al. Substrate specificities of MexAB-OprM, MexCD-OprJ, and MexXYOprM, efflux pumps in Pseudomonas aeruginosa. Antimicrob. Agents Chemother. 44, 3322-3327 (2000).

19 Maseda, H. et al. Enhancement of the mexAB-oprM efflux pump expression by a quorum-sensing autoinducer and its cancellation by a regulator, MexT, of the mexEFoprN efflux pump operon in Pseudomonas aeruginosa. Antimicrob. Agents Chemother. 48, 1320-1328 (2004).

20 Adewoye, L., Sutherland, A., Srikumar, R. \& Poole, K. The MexR repressor of mexABoprM multidrug efflux operon in Pseudomonas aeruginosa: characterization of mutations compromising activity. J. Bacteriol. 184, 4308-4312 (2002).

21 Quale, J., Bratu, S., Gupta, J. \& Landman, D. Interplay of efflux system, ampC, and oprD expression in carbapenem resistance of Pseudomonas aeruginosa clinical isolates. Antimicrob. Agents Chemother. 50, 1633-1641 (2006).

22 Kohler, T., Epp, S. F., Curty, L. K. \& Pechere, J. C. Characterization of MexT, the regulator of the MexE-MexF-OprN multidrug efflux system of Pseudomonas aeruginosa. J. Bacteriol. 181, 6300-6305 (1999).

23 Livermore, D M. Interplay of impermeability and chromosomal beta lactamase activity in imipenem-resistant Pseudomonas aeruginosa. Antimicrob. Agents Chemother. 36, 2046-2048 (1992).

24 Sakyo, S., Tomita, H., Tanimoto, K., Fujimoto, S. \& Ike, Y. Potency of carbapenems for the prevention of carbapenem-resistant mutants of Pseudomonas aeruginosa. J. Antibiot. 59, 220-228 (2006).

$25 \mathrm{Kim}, \mathrm{J}$. Y. et al. Occurrence and mechanisms of amikacin resistance and its association with beta-lactamases in Pseudomonas aeruginosa: a Korean nationwide study. J. Antimicrob. Chemother. 62, 479-483 (2008). 